Supporting Information

Designing Sulfide Borate as a Novel Type of Second-Order Nonlinear Optical Material

Yang Chi, Huai-Guo Xue and Sheng-Ping Guo* 

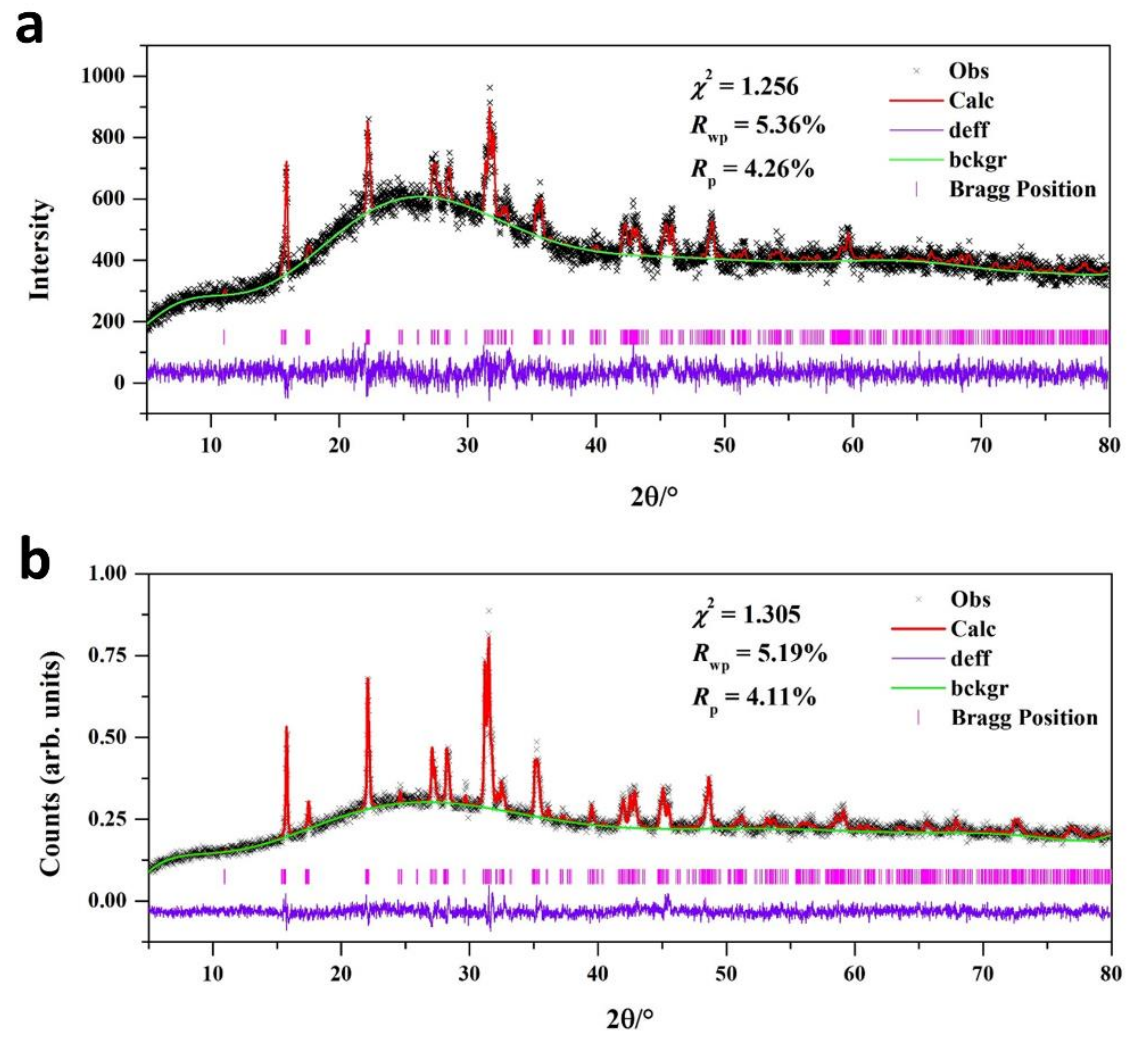

Figure S1. The PXRD patterns of EBOS (a) and EBOSI (b) with Rietveld refinement.

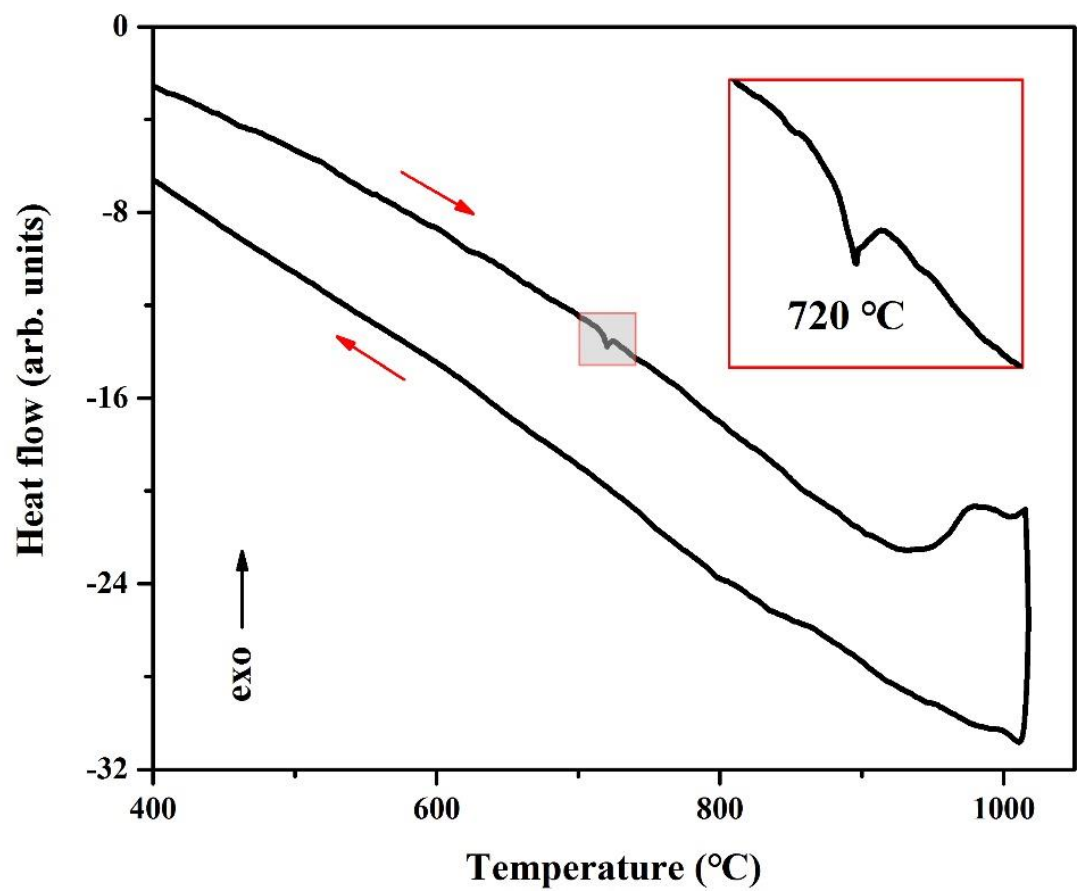

Figure S2. DSC curve of EBOSI. 


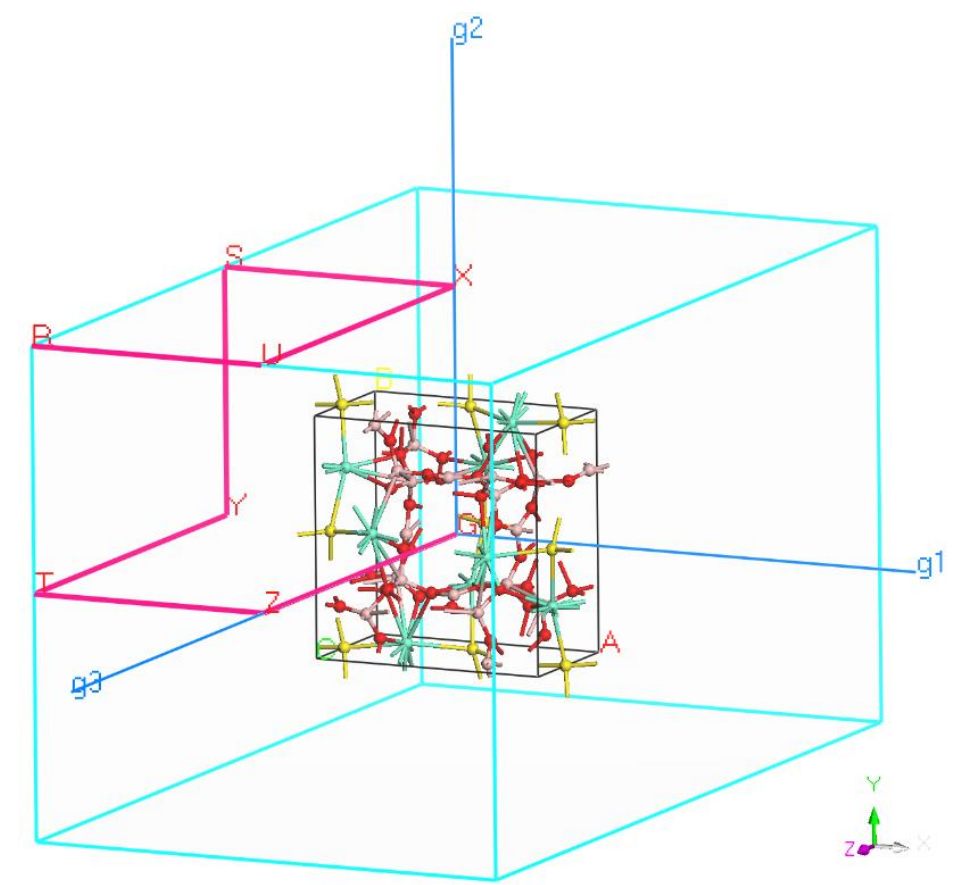

(a)

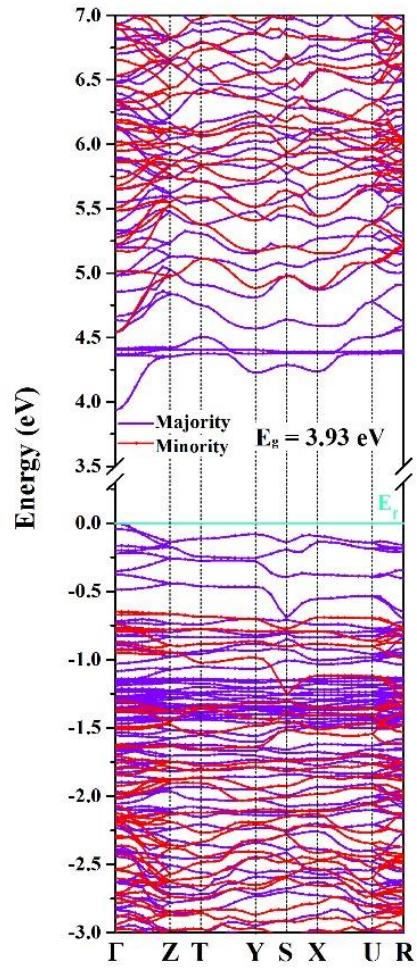

(b) 


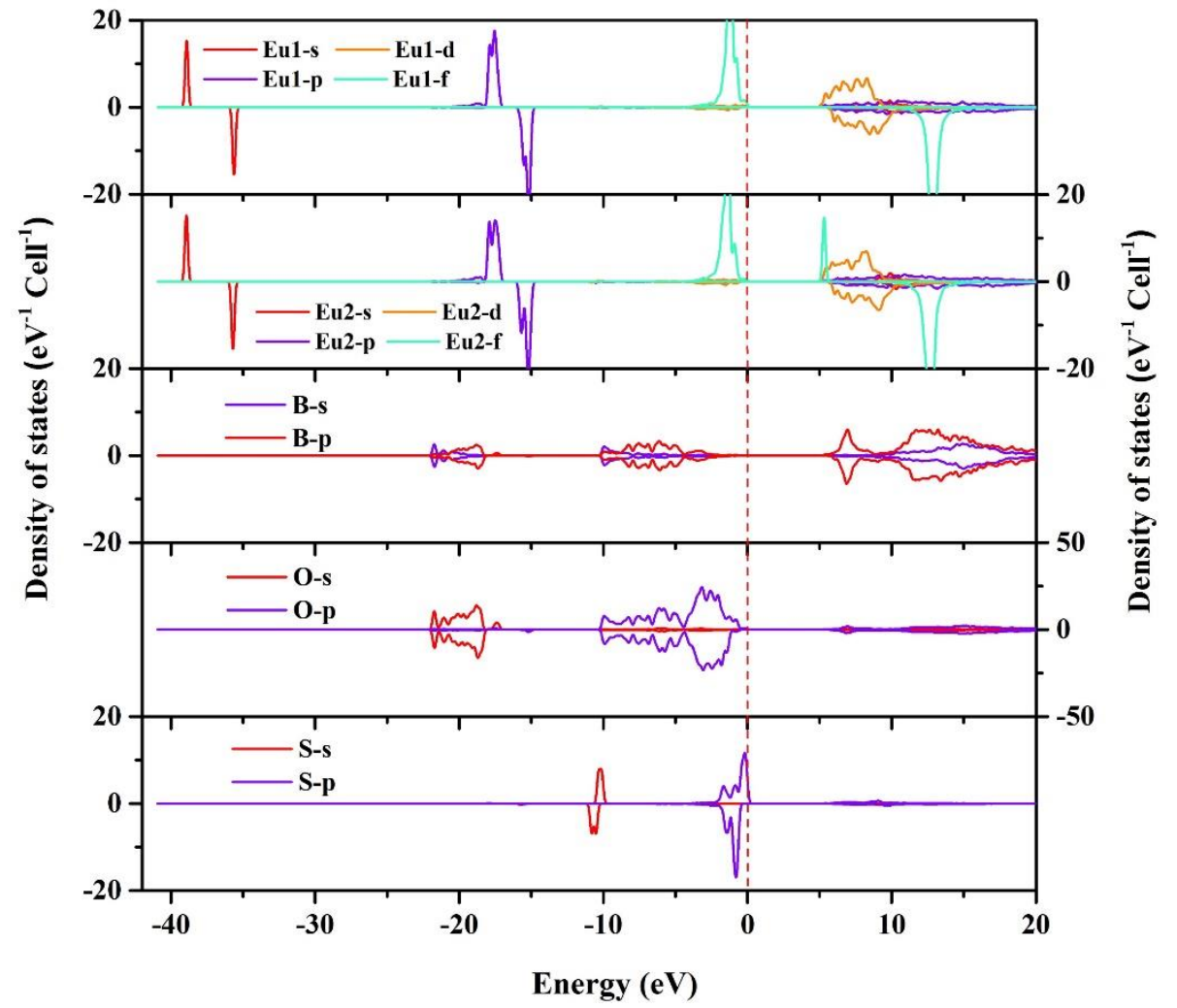

(c)

Figure S3. Brillouin zone paths of primitive cell in the reciprocal space (a), band structure (b), and DOS (c) of EBOS, respectively.

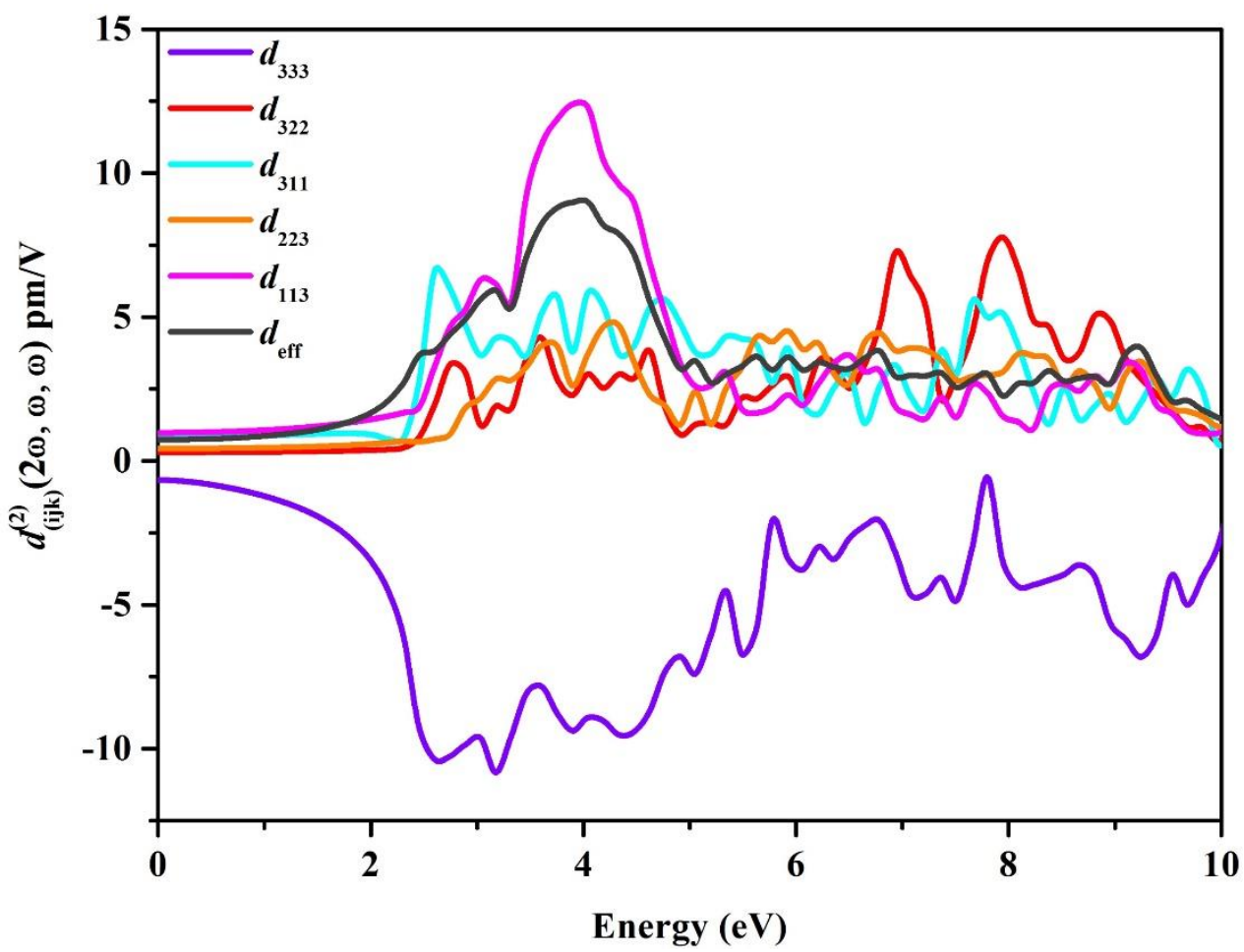

(a) 


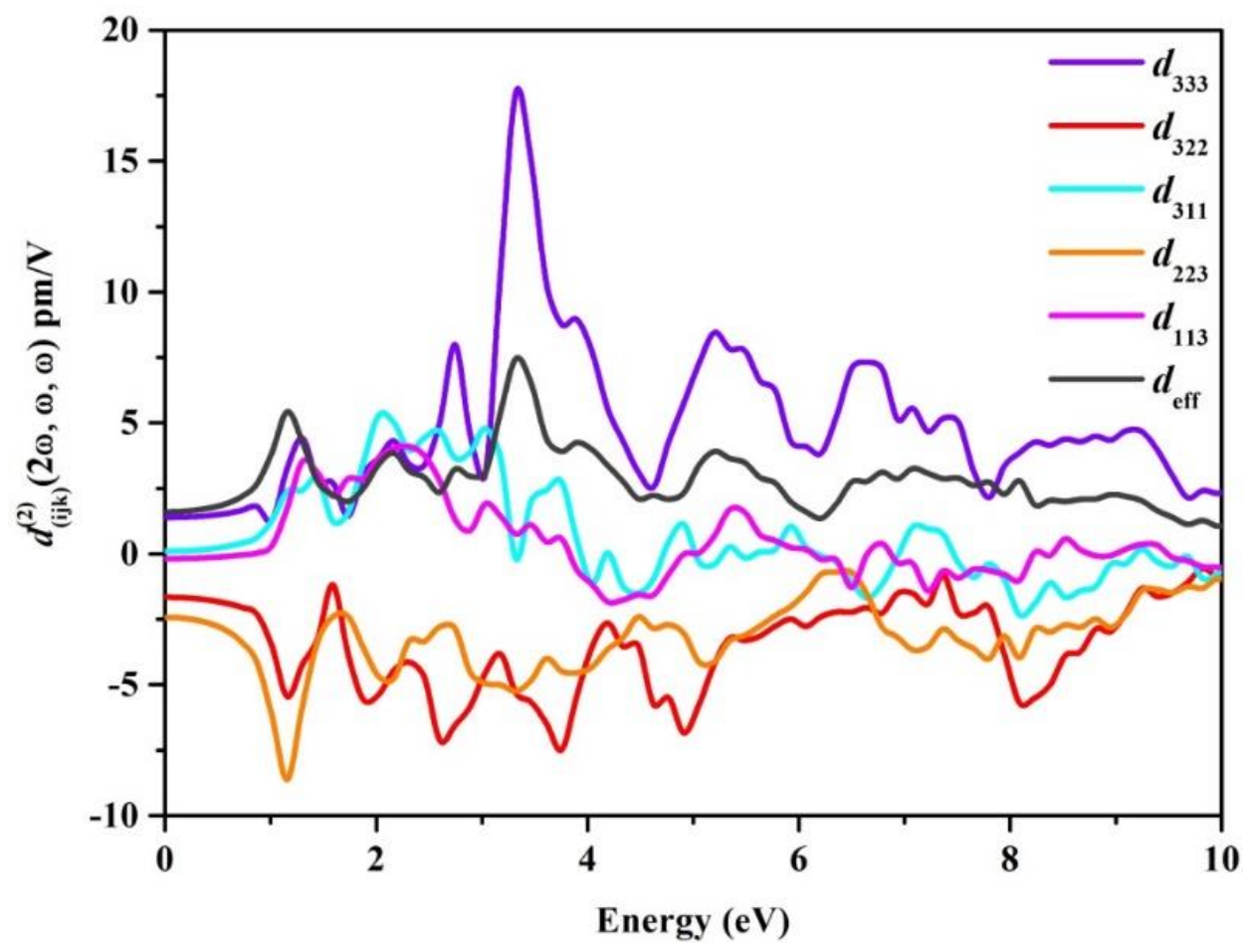

(b)

Figure S4. Calculated frequency dependent NLO coefficients of EBOS (a) and EBOSI (b).

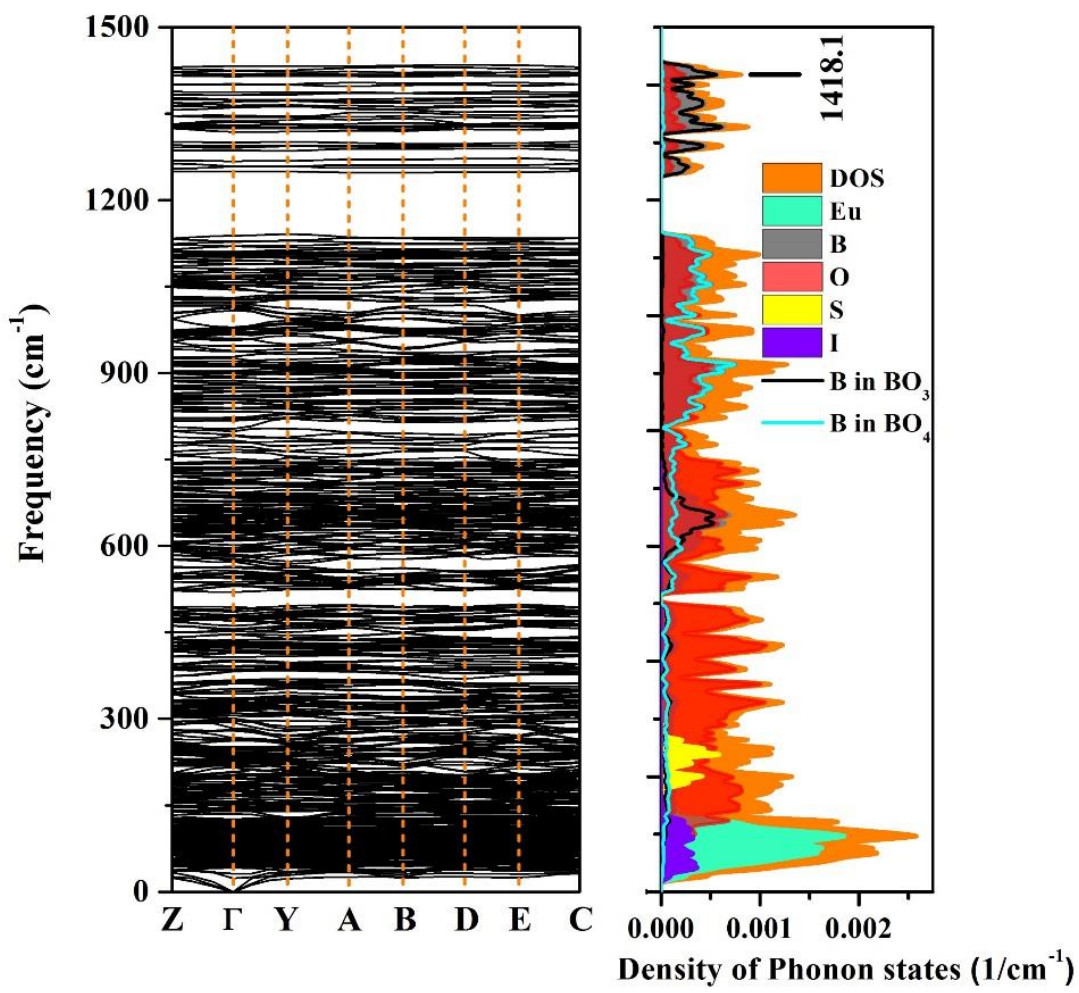

Figure S5. The density of phonon states for EBOSI. 


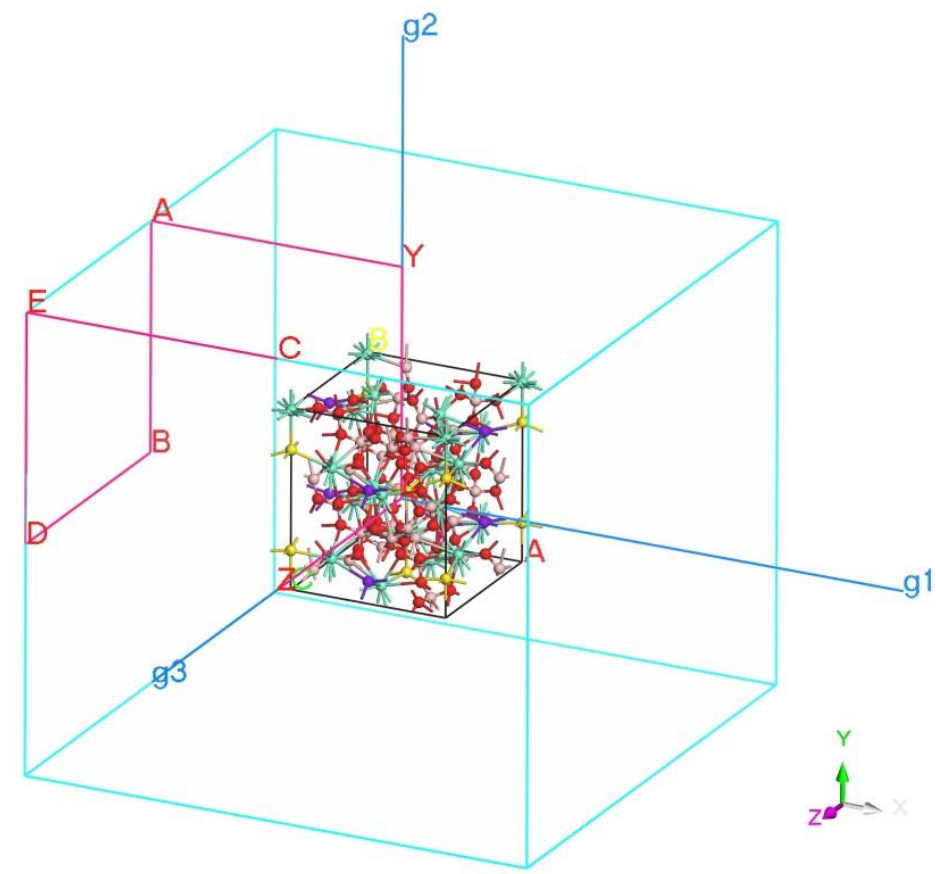

(a)

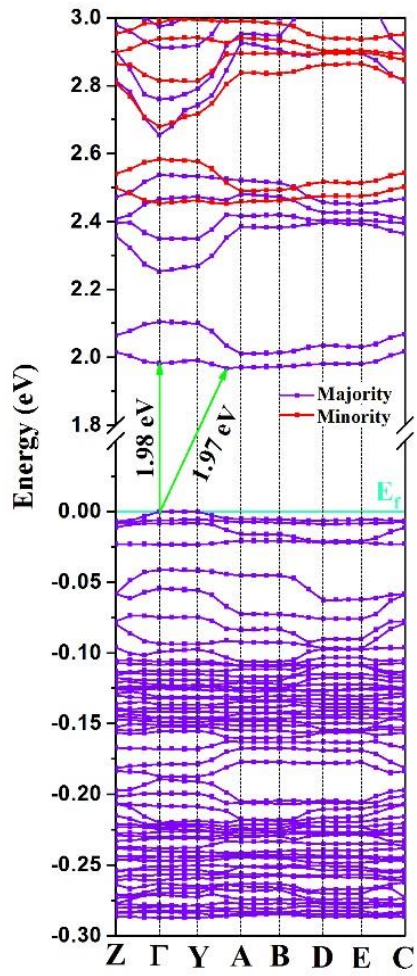

(b)

Figure S6. Brillouin zone paths of primitive cell in the reciprocal space (a) and band structure (b) of EBOSI, respectively. 


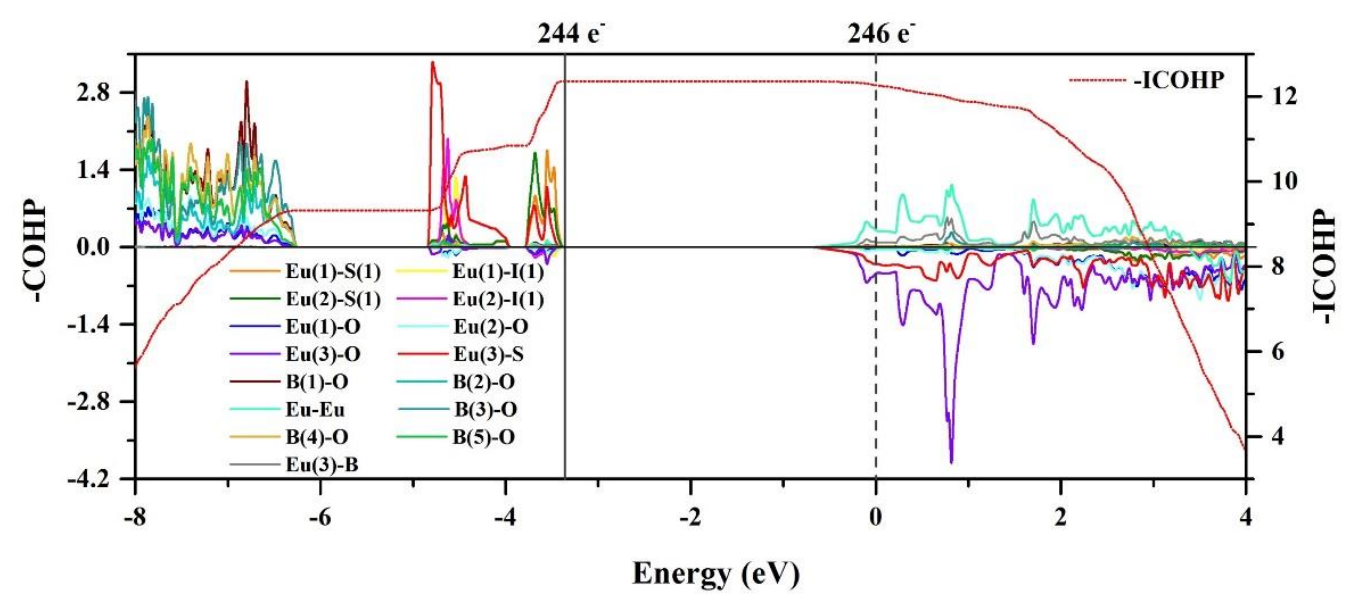

Figure S7. Calculated COHP of EBOSI using the Löwdin downfolding technique. The integrated COHP (ICOHP) is traced by a red line and corresponds to the axis on the right of the plot.

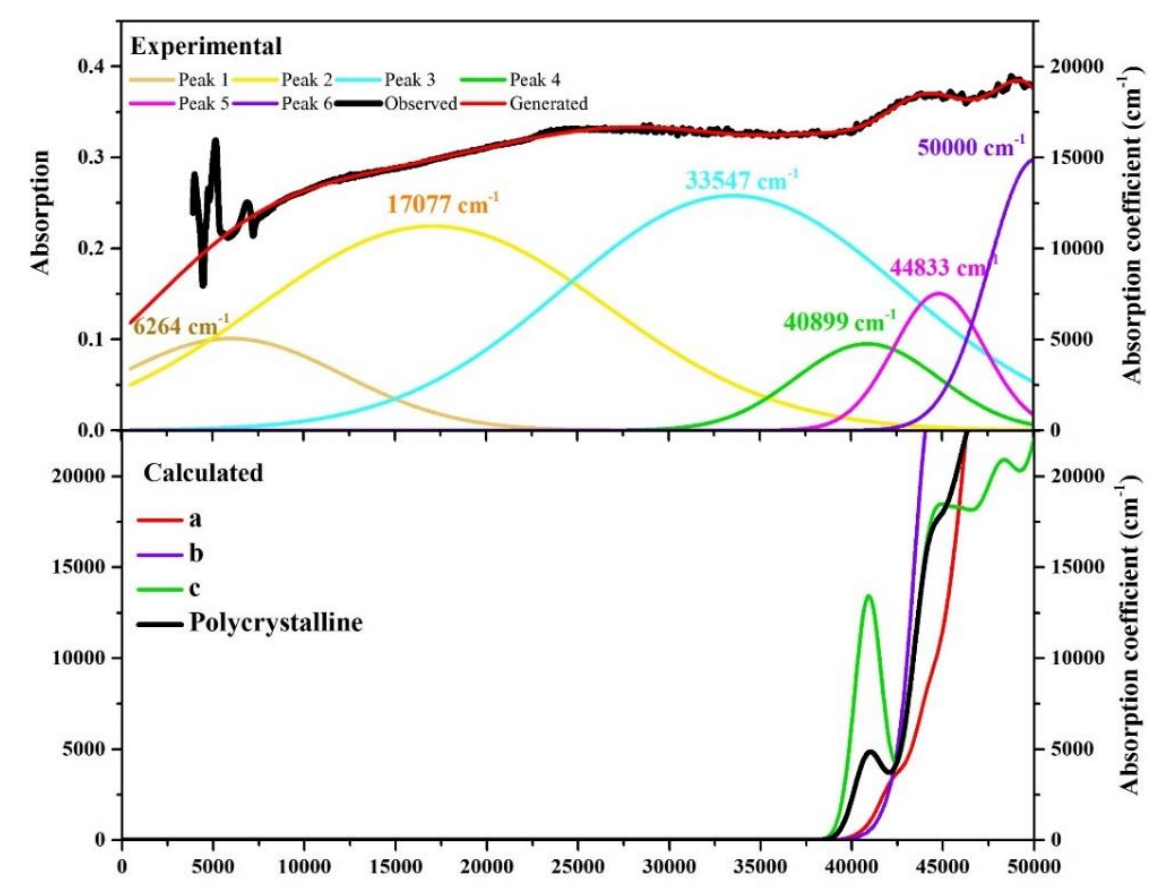

Wave number $\left(\mathrm{cm}^{-1}\right)$

(a) 


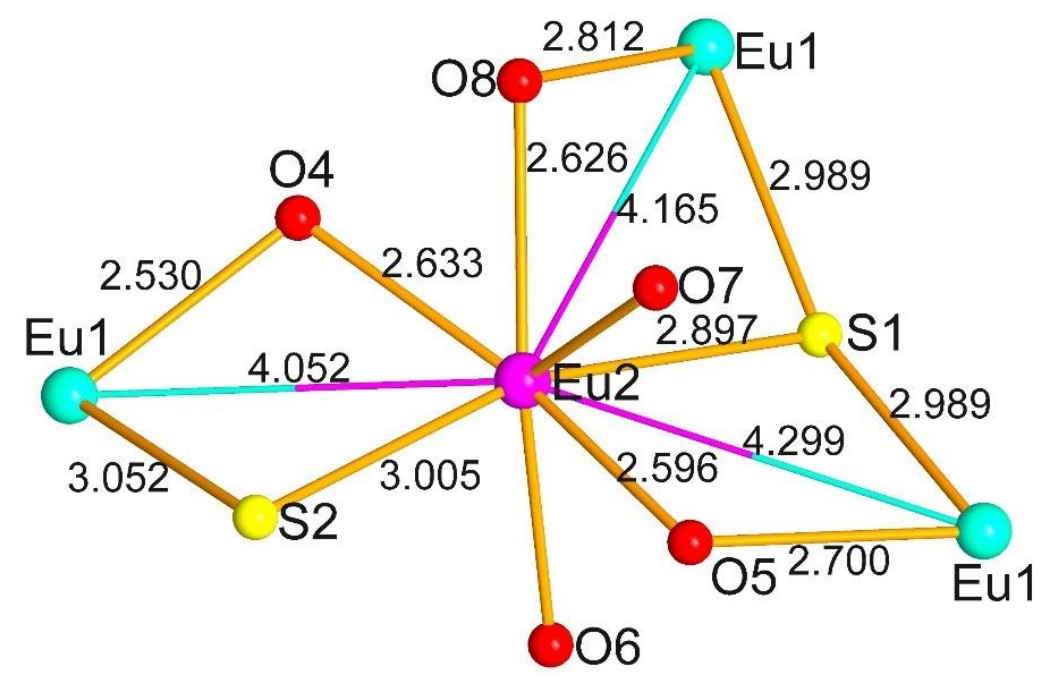

(b)

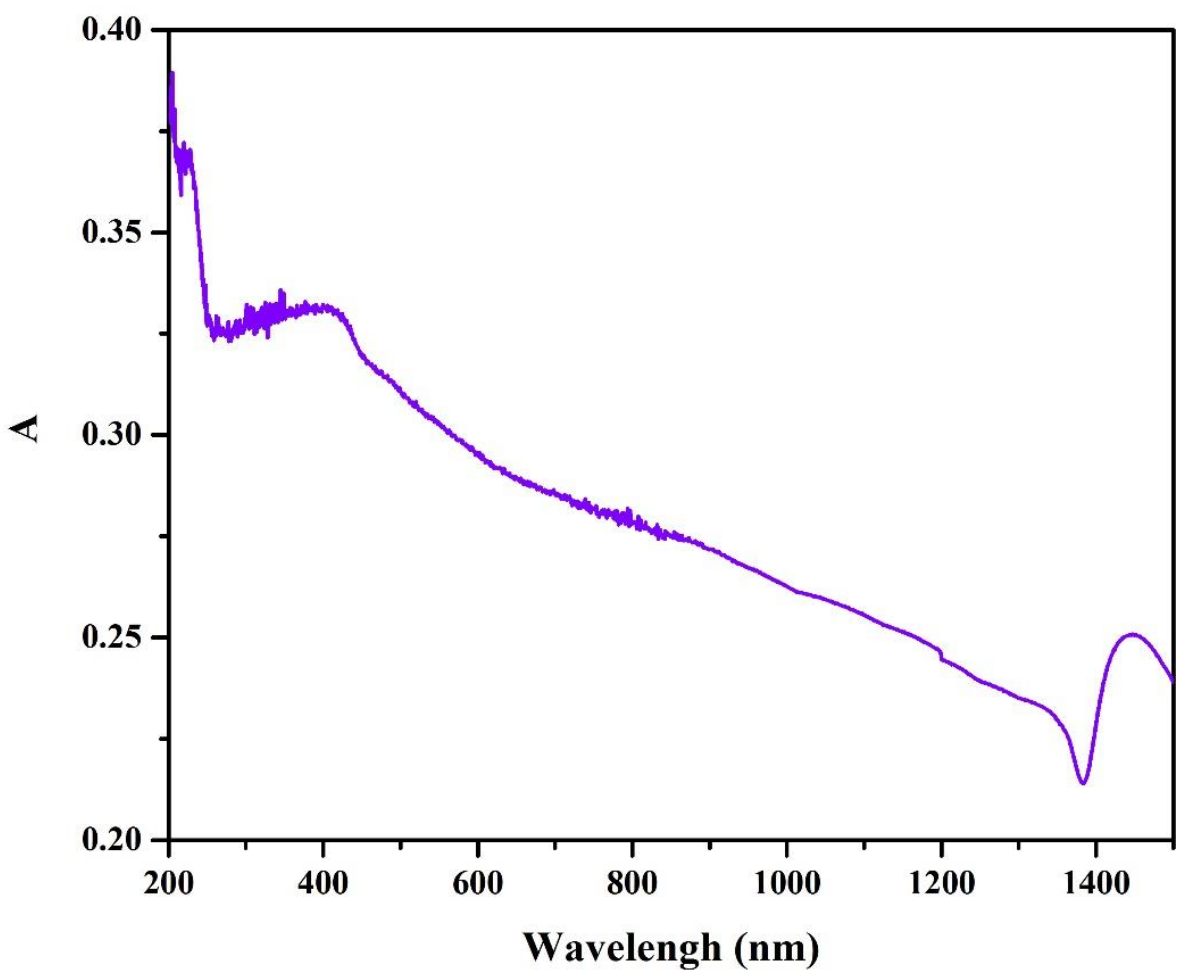

(c)

Figure S8. (a) Decomposed experimental absorption spectra by Gaussian peak fitting and theoretical calculation absorption spectra of EBOS. (b) Interaction between $\operatorname{Eu}(1)\left(\mathrm{Eu}^{2+}\right)$ and $\mathrm{Eu}(2)\left(\mathrm{Eu}^{3+}\right)$ ions are bridged by ligand atom in EBOS. (c) UV-Vis absorption spectrum as a function of wavelength for EBOS. 


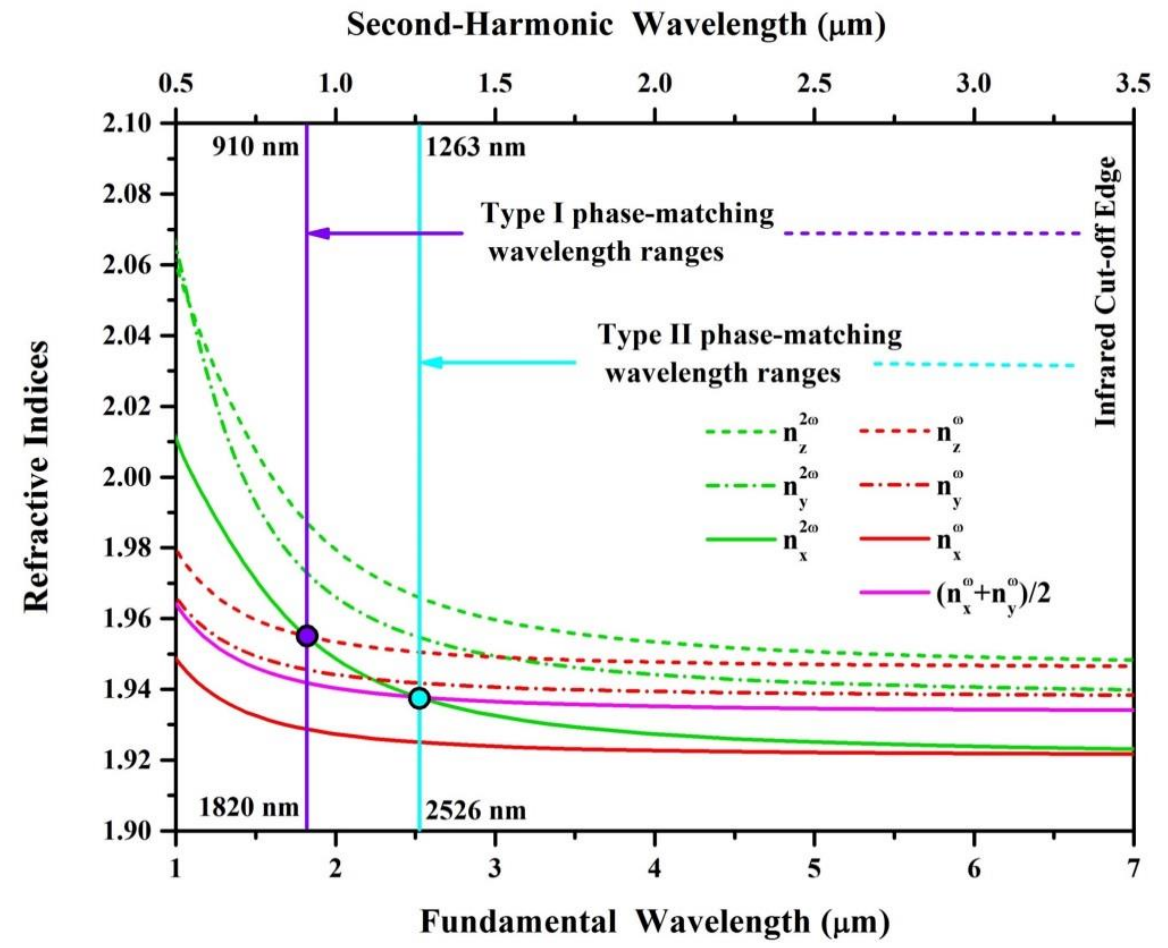

Figure S9. Calculated refractive indices of the fundamental and second harmonic wavelengths for EBOSI. The magenta line represents $\left(\mathrm{n}_{x}(\omega)+\mathrm{n}_{z}(\omega)\right) / 2$. The violet and cyan circled dots represent the Type I and Type II phase-matching wavelength ranges, respectively.
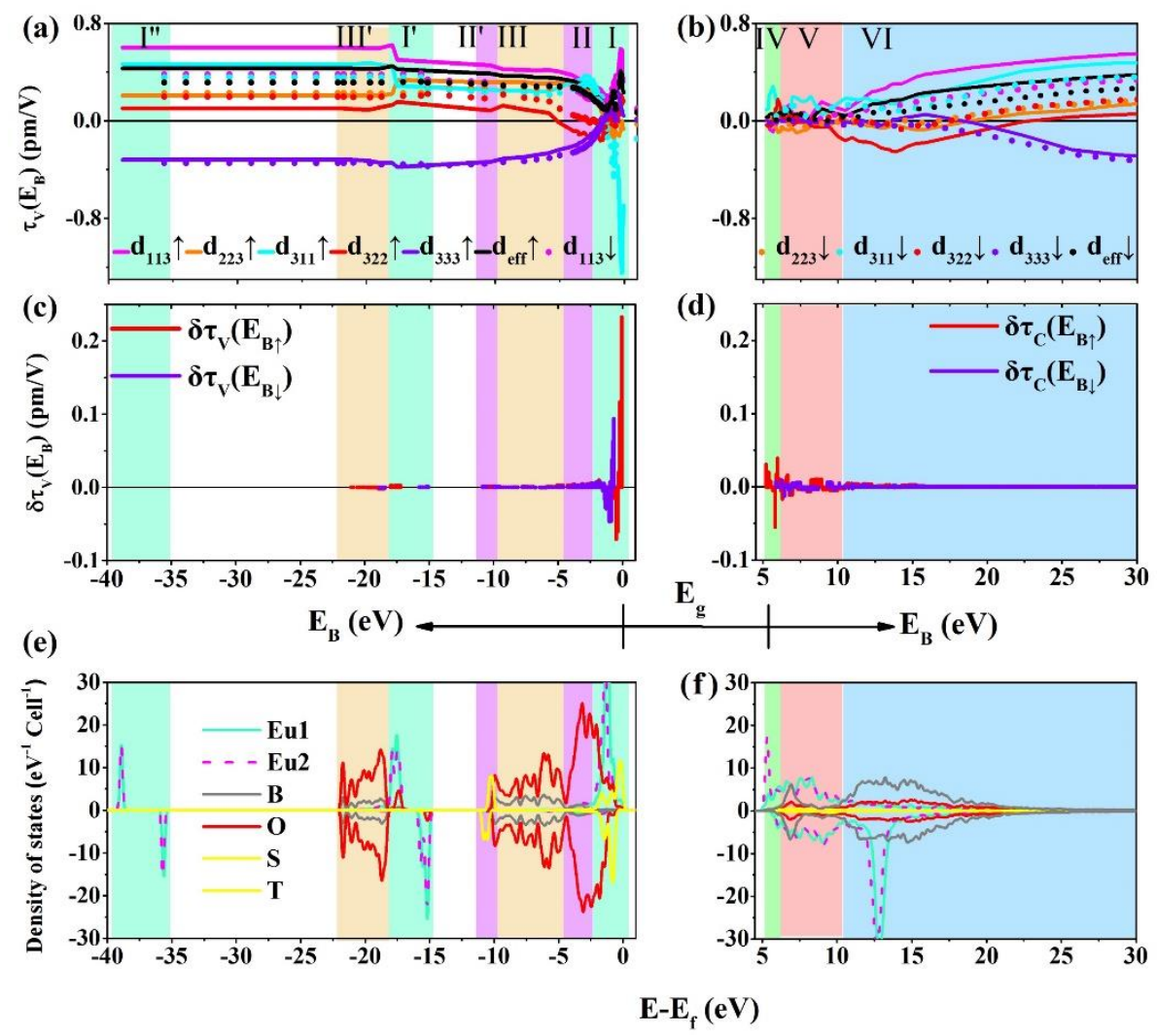
Figure S10. (a) $\tau_{\mathrm{v}}\left(\mathrm{EB}_{\mathrm{B}}\right)-\mathrm{vs.}-\mathrm{E}_{\mathrm{B}}$ plot; (b) $\tau_{\mathrm{c}}\left(\mathrm{EB}_{\mathrm{B}}\right)$-vs.-Eв plot; (c) $\delta \tau_{\mathrm{v}}\left(\mathrm{EB}_{\mathrm{B}}\right)-\mathrm{vs.}$-Eвplot; (d) $\delta \tau_{\mathrm{c}}\left(\mathrm{E}_{\mathrm{B}}\right)-$ vs.-Eв plot; and (e, f) Calculated PDOS of EBOS.

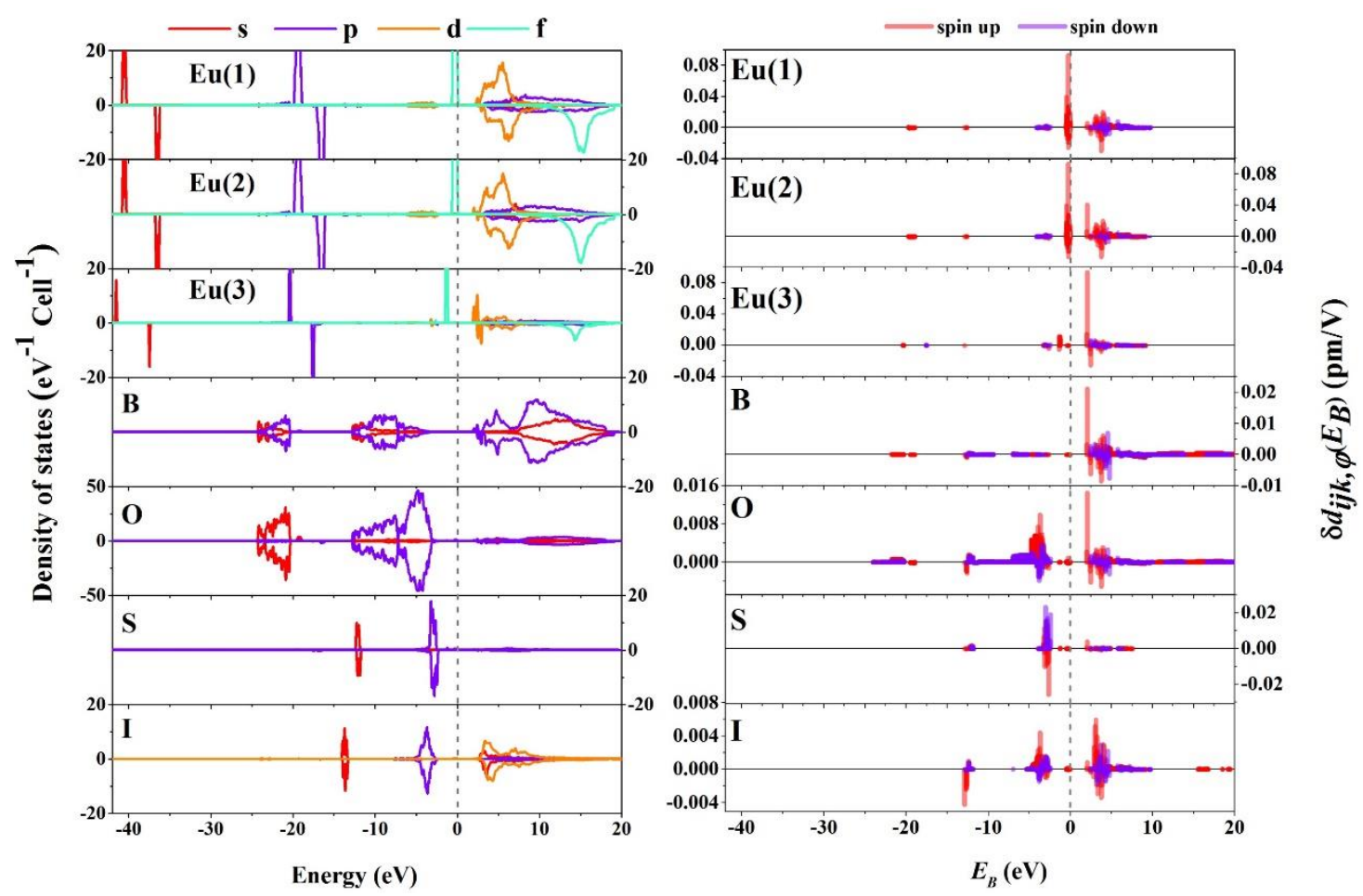

Figure S11. Calculated PDOS (left), and $\delta d_{i j k, \varphi}\left(E_{B}\right)$-vs. $-E_{B}$ plot (right) of EBOSI.

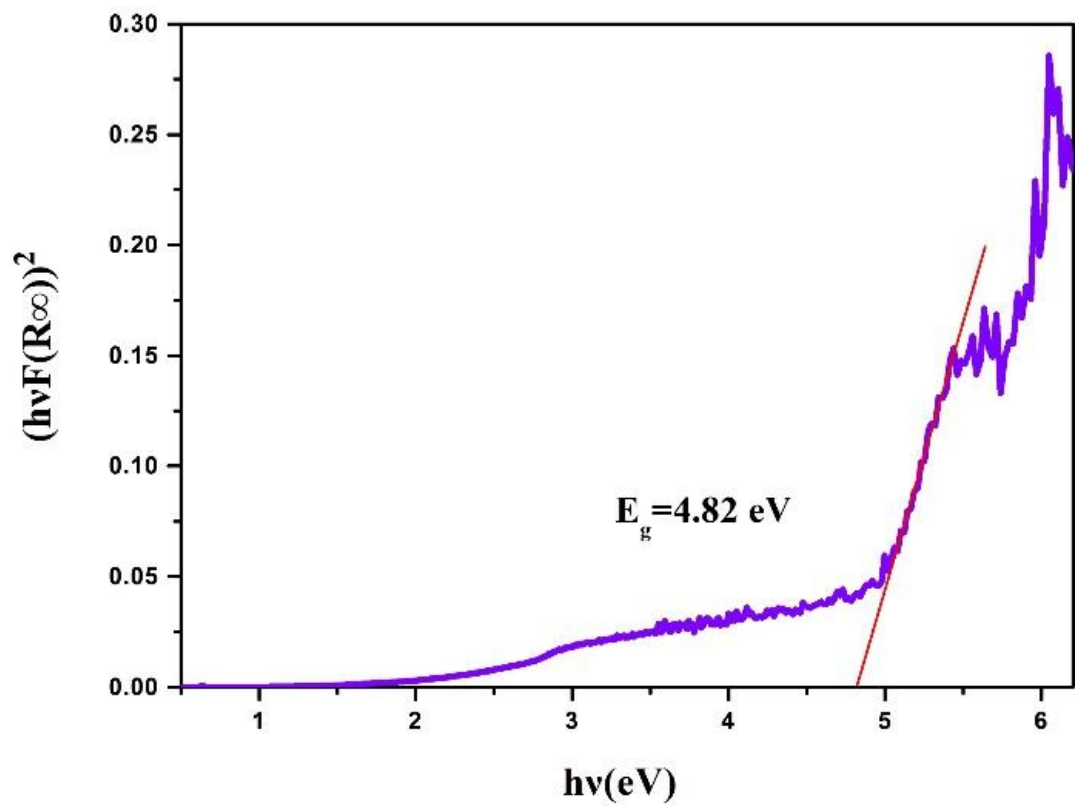

Figure S12. Tauc plot of EBOS. 
Table S1. Atomic coordinates $\left(\times 10^{4}\right)$ and equivalent isotropic displacement parameters $\left(U_{\mathrm{eq}}{ }^{a}\right.$, $\AA^{2} \times 10^{3}$ ) for EBOS.

\begin{tabular}{|c|c|c|c|c|c|}
\hline Atom & Wyck. site & $x$ & $y$ & $z$ & $U_{\mathrm{eq}} / \AA^{2}$ \\
\hline $\mathrm{Eu}(1)$ & $4 c$ & 2417.9(9) & $5282.3(8)$ & $9573(2)$ & $17.8(3)$ \\
\hline $\operatorname{Eu}(2)$ & $4 c$ & $361.4(8)$ & 7519.9(13) & $6262(2)$ & $20.7(3)$ \\
\hline $\mathrm{B}(1)$ & $4 c$ & $2853(15)$ & $6950(16)$ & $4600(50)$ & $6(4)$ \\
\hline $\mathrm{B}(2)$ & $4 c$ & $2506(19)$ & $4720(19)$ & $4190(30)$ & $8(5)$ \\
\hline $\mathrm{B}(3)$ & $4 c$ & 2130(19) & $8090(20)$ & $11440(40)$ & $13(4)$ \\
\hline $\mathrm{B}(4)$ & $4 c$ & $-1790(20)$ & $7217(19)$ & $3150(40)$ & $8(5)$ \\
\hline $\mathrm{B}(5)$ & $4 c$ & $-99(19)$ & $7590(20)$ & $940(40)$ & $12(5)$ \\
\hline$S(1)$ & $2 a$ & 0 & 10000 & $5458(13)$ & $14.8(16)$ \\
\hline$S(2)$ & $2 b$ & 0 & 5000 & $7512(13)$ & $12.1(16)$ \\
\hline $\mathrm{O}(1)$ & $4 c$ & $1060(12)$ & $7528(13)$ & $10370(20)$ & $15(3)$ \\
\hline $\mathrm{O}(2)$ & $4 c$ & $2895(11)$ & $4338(11)$ & $6120(20)$ & $10(3)$ \\
\hline $\mathrm{O}(3)$ & $4 c$ & $2227(12)$ & $3947(13)$ & $2690(20)$ & $14(3)$ \\
\hline $\mathrm{O}(4)$ & $4 c$ & $2578(13)$ & $6892(12)$ & $6880(20)$ & $12(3)$ \\
\hline $\mathrm{O}(5)$ & $4 c$ & $3116(11)$ & $7505(13)$ & 10381(19) & $9(3)$ \\
\hline $\mathrm{O}(6)$ & $4 c$ & $-870(12)$ & $7855(12)$ & $9310(20)$ & $14(3)$ \\
\hline $\mathrm{O}(7)$ & $4 c$ & $-524(13)$ & $7308(13)$ & $2790(30)$ & $17(3)$ \\
\hline $\mathrm{O}(8)$ & $4 c$ & $2123(13)$ & $7904(12)$ & $3680(20)$ & $8(3)$ \\
\hline $\mathrm{O}(9)$ & $4 c$ & $2506(13)$ & $5873(13)$ & $3610(20)$ & $15(3)$ \\
\hline
\end{tabular}

${ }^{a} U_{\text {eq }}$ is defined as one third of the trace of the orthogonalized $U_{i j}$ tensor. 
Table S2. Atomic coordinates $\left(\times 10^{4}\right)$ and equivalent isotropic displacement parameters $\left(U_{\mathrm{eq}}{ }^{a}\right.$, $\AA^{2} \times 10^{3}$ ) for EBOSI.

\begin{tabular}{|c|c|c|c|c|c|c|}
\hline Atom & Wyck. site & $x$ & $y$ & $z$ & Occupancy & $\boldsymbol{U}_{\mathrm{eq}} / \AA^{2}$ \\
\hline $\operatorname{Eu}(1)$ & $4 c$ & $-2531.5(4)$ & $-5396.9(3)$ & $-9685.1(6)$ & 1 & $12.49(6)$ \\
\hline $\mathrm{Eu}(2)$ & $4 c$ & $-487.2(3)$ & $-7647.4(3)$ & $-6173.2(5)$ & 1 & $10.62(6)$ \\
\hline $\operatorname{Eu}(3)$ & $2 a$ & 0 & -10000 & $-283(2)$ & 0.5 & $15.67(18)$ \\
\hline $\mathrm{B}(1)$ & $4 c$ & $-2943(5)$ & $-6977(5)$ & $-4668(10)$ & 1 & $3.6(8)$ \\
\hline $\mathrm{B}(2)$ & $4 c$ & $-2533(7)$ & $-4752(7)$ & $-4278(9)$ & 1 & $6.6(10)$ \\
\hline $\mathrm{B}(3)$ & $4 c$ & $-2208(6)$ & $-8054(6)$ & $-11480(9)$ & 1 & $4(1)$ \\
\hline $\mathrm{B}(4)$ & $4 c$ & $1724(6)$ & $-7148(6)$ & $-3173(9)$ & 1 & $6.4(10)$ \\
\hline $\mathrm{B}(5)$ & $4 c$ & $30(7)$ & $-7509(6)$ & $-917(11)$ & 1 & $8.0(13)$ \\
\hline $\mathrm{I}(1)$ & $2 b$ & 0 & -5000 & $-7566.7(14)$ & 1 & $18.56(13)$ \\
\hline $\mathrm{S}(1 \mathrm{~A})$ & $2 a$ & 0 & -10000 & $-4664(8)$ & $0.598(17)$ & $9.7(12)$ \\
\hline $\mathrm{S}(1 \mathrm{~B})$ & $2 a$ & 0 & -10000 & $-5792(10)$ & $0.402(17)$ & $5.8(15)$ \\
\hline $\mathrm{O}(1)$ & $4 c$ & $-1126(5)$ & $-7525(4)$ & $-10477(8)$ & 1 & $12.8(10)$ \\
\hline $\mathrm{O}(2)$ & $4 c$ & $-2879(4)$ & $-4340(4)$ & $-6127(10)$ & 1 & $9.7(7)$ \\
\hline $\mathrm{O}(3)$ & $4 c$ & $-2215(5)$ & $-4004(4)$ & $-2721(7)$ & 1 & $13.5(9)$ \\
\hline $\mathrm{O}(4)$ & $4 c$ & $-2677(4)$ & $-6996(4)$ & $-6891(7)$ & 1 & $4.7(7)$ \\
\hline $\mathrm{O}(5)$ & $4 c$ & $-3172(4)$ & $-7562(4)$ & $-10341(7)$ & 1 & $5.7(7)$ \\
\hline $\mathrm{O}(6)$ & $4 c$ & $774(4)$ & $-7891(4)$ & $-9414(7)$ & 1 & $9.1(8)$ \\
\hline $\mathrm{O}(7)$ & $4 c$ & 462(4) & $-7139(5)$ & $-2751(7)$ & 1 & $12.2(8)$ \\
\hline $\mathrm{O}(8)$ & $4 c$ & $-2280(4)$ & $-7905(4)$ & $-13677(7)$ & 1 & $6.4(8)$ \\
\hline $\mathrm{O}(9)$ & $4 c$ & $-2598(5)$ & $-5885(4)$ & $-3714(7)$ & 1 & $8.4(8)$ \\
\hline
\end{tabular}

\footnotetext{
${ }^{a} U_{\text {eq }}$ is defined as one third of the trace of the orthogonalized $U_{i j}$ tensor.
} 
Table S3. Important bond lengths ( $)$ for EBOS.

\begin{tabular}{|c|c|c|c|}
\hline Bond & Length/Å & Bond & Length/Å \\
\hline $\operatorname{Eu}(1)-S(1) \# 3$ & $2.988(2)$ & $\mathrm{B}(1)-\mathrm{O}(6) \# 6$ & $1.47(2)$ \\
\hline $\operatorname{Eu}(1)-S(2)$ & $3.053(4)$ & $\mathrm{B}(1)-\mathrm{O}(8)$ & $1.48(2)$ \\
\hline $\mathrm{Eu}(1)-\mathrm{O}(1)$ & $3.023(14)$ & $\mathrm{B}(1)-\mathrm{O}(9)$ & $1.44(2)$ \\
\hline $\mathrm{Eu}(1)-\mathrm{O}(2)$ & $2.527(15)$ & $\mathrm{B}(2)-\mathrm{O}(2)$ & $1.39(3)$ \\
\hline $\mathrm{Eu}(1)-\mathrm{O}(3) \# 1$ & $2.528(14)$ & $\mathrm{B}(2)-\mathrm{O}(3)$ & $1.35(3)$ \\
\hline $\mathrm{Eu}(1)-\mathrm{O}(4)$ & $2.529(14)$ & $\mathrm{B}(2)-\mathrm{O}(9)$ & $1.37(3)$ \\
\hline $\mathrm{Eu}(1)-\mathrm{O}(5)$ & $2.699(14)$ & $\mathrm{B}(3)-\mathrm{O}(1)$ & $1.53(3)$ \\
\hline $\mathrm{Eu}(1)-\mathrm{O}(8) \# 4$ & $2.813(13)$ & $\mathrm{B}(3)-\mathrm{O}(2) \# 8$ & $1.44(3)$ \\
\hline $\mathrm{Eu}(1)-\mathrm{O}(9) \# 1$ & $2.686(13)$ & $\mathrm{B}(3)-\mathrm{O}(5)$ & $1.46(3)$ \\
\hline $\mathrm{Eu}(2)-\mathrm{S}(1)$ & $2.897(2)$ & $\mathrm{B}(3)-\mathrm{O}(8) \# 1$ & $1.46(3)$ \\
\hline $\mathrm{Eu}(2)-\mathrm{S}(2)$ & $3.005(3)$ & $\mathrm{B}(4)-\mathrm{O}(3) \# 9$ & $1.45(3)$ \\
\hline $\mathrm{Eu}(2)-\mathrm{O}(1)$ & $2.761(14)$ & $\mathrm{B}(4)-\mathrm{O}(4) \# 5$ & $1.49(3)$ \\
\hline $\mathrm{Eu}(2)-\mathrm{O}(4)$ & $2.633(15)$ & $\mathrm{B}(4)-\mathrm{O}(5) \# 5$ & $1.48(3)$ \\
\hline $\mathrm{Eu}(2)-\mathrm{O}(5) \# 5$ & $2.598(13)$ & $\mathrm{B}(4)-\mathrm{O}(7)$ & $1.45(3)$ \\
\hline $\mathrm{Eu}(2)-\mathrm{O}(6)$ & $2.435(15)$ & $\mathrm{B}(5)-\mathrm{O}(1) \# 7$ & $1.36(3)$ \\
\hline $\mathrm{Eu}(2)-\mathrm{O}(7)$ & $2.460(16)$ & $\mathrm{B}(5)-\mathrm{O}(6) \# 7$ & $1.40(3)$ \\
\hline $\mathrm{Eu}(2)-\mathrm{O}(8)$ & $2.629(14)$ & $\mathrm{B}(5)-\mathrm{O}(7)$ & $1.33(3)$ \\
\hline $\mathrm{B}(1)-\mathrm{O}(4)$ & $1.51(3)$ & & \\
\hline
\end{tabular}

Symmetry transformations used to generate equivalent atoms: $1 \#+x,+y, 1+z ; 2 \# 1 / 2-x,-1 / 2+y$, $-1 / 2+z ; 3 \# 1 / 2+x, 3 / 2-y, 1 / 2+z ; 4 \# 1 / 2-x,-1 / 2+y, 1 / 2+z ; 5 \#-1 / 2+x, 3 / 2-y,-1 / 2+z ; 6 \# 1 / 2+x, 3 / 2-$ $y,-1 / 2+z ; 7 \#+x,+y,-1+z ; 8 \# 1 / 2-x, 1 / 2+y, 1 / 2+z ; 9 \#-x, 1-y,+z ; 10 \# 1 / 2-x, 1 / 2+y,-1 / 2+z ; 11 \#$ $-x, 2-y,+z ; 12 \#-1 / 2+x, 3 / 2-y, 1 / 2+z$. 
Table S4. Important bond lengths $(\AA)$ for EBOSI.

\begin{tabular}{|c|c|c|c|}
\hline Bond & Length/Å & Bond & Length/Å \\
\hline $\operatorname{Eu}(1)-\mathrm{I}(1)$ & $3.260(1)$ & $\mathrm{Eu}(3)-\mathrm{O}(2) \# 4$ & $2.620(5)$ \\
\hline $\mathrm{Eu}(1)-\mathrm{S}(1 \mathrm{~A}) \# 2$ & $2.883(1)$ & $\mathrm{Eu}(3)-\mathrm{O}(6) \# 5$ & $2.655(5)$ \\
\hline $\mathrm{Eu}(1)-\mathrm{S}(1 \mathrm{~B}) \# 2$ & $2.971(2)$ & $\mathrm{Eu}(3)-\mathrm{O}(9) \# 4$ & $3.123(5)$ \\
\hline $\mathrm{Eu}(1)-\mathrm{O}(1)$ & $2.988(5)$ & $\mathrm{B}(1)-\mathrm{O}(4)$ & $1.479(8)$ \\
\hline $\mathrm{Eu}(1)-\mathrm{O}(2)$ & $2.648(6)$ & $\mathrm{B}(1)-\mathrm{O}(6) \# 9$ & $1.496(8)$ \\
\hline $\mathrm{Eu}(1)-\mathrm{O}(3) \# 1$ & $2.574(5)$ & $\mathrm{B}(1)-\mathrm{O}(8) \# 5$ & $1.466(7)$ \\
\hline $\mathrm{Eu}(1)-\mathrm{O}(4)$ & $2.597(5)$ & $\mathrm{B}(1)-\mathrm{O}(9)$ & $1.461(8)$ \\
\hline $\mathrm{Eu}(1)-\mathrm{O}(5)$ & $2.642(4)$ & $\mathrm{B}(2)-\mathrm{O}(2)$ & $1.354(9)$ \\
\hline $\mathrm{Eu}(1)-\mathrm{O}(8) \# 3$ & $2.960(5)$ & $\mathrm{B}(2)-\mathrm{O}(3)$ & $1.381(8)$ \\
\hline $\mathrm{Eu}(1)-\mathrm{O}(9) \# 1$ & $2.683(4)$ & $\mathrm{B}(2)-\mathrm{O}(9)$ & $1.362(9)$ \\
\hline $\mathrm{Eu}(2)-\mathrm{I}(1)$ & $3.238(1)$ & $\mathrm{B}(3)-\mathrm{O}(1)$ & $1.535(8)$ \\
\hline $\mathrm{Eu}(2)-\mathrm{S}(1 \mathrm{~A})$ & $2.944(2)$ & $\mathrm{B}(3)-\mathrm{O}(2) \# 10$ & $1.506(8)$ \\
\hline $\mathrm{Eu}(2)-\mathrm{S}(1 \mathrm{~B})$ & $2.786(8)$ & $\mathrm{B}(3)-\mathrm{O}(5)$ & $1.452(8)$ \\
\hline $\mathrm{Eu}(2)-\mathrm{O}(1)$ & $2.899(5)$ & $\mathrm{B}(3)-\mathrm{O}(8)$ & $1.442(7)$ \\
\hline $\mathrm{Eu}(2)-\mathrm{O}(4)$ & $2.675(4)$ & $\mathrm{B}(4)-\mathrm{O}(3) \# 11$ & $1.477(8)$ \\
\hline $\mathrm{Eu}(2)-\mathrm{O}(5) \# 4$ & $2.734(5)$ & $\mathrm{B}(4)-\mathrm{O}(4) \# 4$ & $1.467(8)$ \\
\hline $\mathrm{Eu}(2)-\mathrm{O}(6)$ & $2.577(5)$ & $\mathrm{B}(4)-\mathrm{O}(5) \# 4$ & $1.455(8)$ \\
\hline $\mathrm{Eu}(2)-\mathrm{O}(7)$ & $2.550(5)$ & $\mathrm{B}(4)-\mathrm{O}(7)$ & $1.480(8)$ \\
\hline $\mathrm{Eu}(2)-\mathrm{O}(8) \# 5$ & $2.645(5)$ & $\mathrm{B}(5)-\mathrm{O}(1) \# 5$ & $1.363(10)$ \\
\hline $\mathrm{Eu}(3)-\mathrm{S}(1 \mathrm{~A})$ & $2.850(5)$ & $\mathrm{B}(5)-\mathrm{O}(6) \# 5$ & $1.374(9)$ \\
\hline $\operatorname{Eu}(3)-S(1 \mathrm{~B}) \# 5$ & $2.923(7)$ & $\mathrm{B}(5)-\mathrm{O}(7)$ & $1.361(9)$ \\
\hline
\end{tabular}

Symmetry transformations used to generate equivalent atoms: $\# 1+x,+y,-1+z ; \# 2-1 / 2+x,-3 / 2-$ $y,-1 / 2+z ; \# 3-1 / 2-x, 1 / 2+y, 1 / 2+z ; \# 41 / 2+x,-3 / 2-y, 1 / 2+z ; \# 5+x,+y, 1+z ; \# 6-1 / 2-x,-1 / 2+y$, $1 / 2+z ; \# 7-x,-2-y,+z ; \# 8-x,-2-y, 1+z ; \# 9-1 / 2+x,-3 / 2-y, 1 / 2+z ; \# 10-1 / 2-x,-1 / 2+y,-1 / 2+z ; \# 11$ $-x,-1-y,+z$. 
Table S5. The Brillouin zone paths in the reciprocal space for EBOS.

\begin{tabular}{cccc}
\hline K-point & $\begin{array}{c}\text { Fractional } \\
\text { coordinates }\end{array}$ & K-point & $\begin{array}{c}\text { Fractional } \\
\text { coordinates }\end{array}$ \\
\hline$\Gamma$ & $(0,0,0)$ & $\mathrm{Z}$ & $(0,0,0.5)$ \\
$\mathrm{T}$ & $(-0.5,0,0.5)$ & $\mathrm{Y}$ & $(-0.5,0,0)$ \\
$\mathrm{S}$ & $(-0.5,0.5,0)$ & $\mathrm{X}$ & $(0,0.5,0)$ \\
$\mathrm{U}$ & $(0,0.5,0.5)$ & $\mathrm{R}$ & $(-0.5,0.5,0.5)$ \\
\hline
\end{tabular}

Table S6. The 4f-orbitals occupation numbers and Mulliken spin Populations of Eu atoms for EBOS.

\begin{tabular}{|c|c|c|c|c|}
\hline \multirow[b]{2}{*}{ Atom } & \multicolumn{2}{|l|}{$\mathrm{U}=\mathbf{0} \mathbf{e V}$} & \multicolumn{2}{|l|}{$\mathrm{U}=6 \mathrm{eV}$} \\
\hline & $\begin{array}{c}\text { Occupation numbers } \\
\text { (up/down) }\end{array}$ & $\begin{array}{c}\text { Band } \\
\text { gap }\end{array}$ & $\begin{array}{c}\text { Occupation numbers } \\
\text { (up/down) }\end{array}$ & Band gap \\
\hline $\mathrm{Eu}(1)$ & $6.64 / 0.07$ & & $7.00 / 0.04$ & \\
\hline $\mathrm{Eu}(2)$ & $6.62 / 0.09$ & $0 \mathrm{eV}$ & $6.02 / 0.05$ & $3.93 \mathrm{eV}$ \\
\hline
\end{tabular}

Table S7. The Brillouin zone paths in the reciprocal space for EBOSI.

\begin{tabular}{cccc}
\hline K-point & $\begin{array}{c}\text { Fractional } \\
\text { coordinates }\end{array}$ & K-point & $\begin{array}{c}\text { Fractional } \\
\text { coordinates }\end{array}$ \\
\hline $\mathrm{Z}$ & $(0,0,0.5)$ & $\mathrm{B}$ & $(-0.5,0,0)$ \\
$\Gamma$ & $(0,0,0)$ & $\mathrm{D}$ & $(-0.5,0,0.5)$ \\
$\mathrm{Y}$ & $(0,0.5,0)$ & $\mathrm{E}$ & $(-0.5,0.5,0.5)$ \\
$\mathrm{A}$ & $(-0.5,0.5,0)$ & $\mathrm{C}$ & $(0,0.5,0.5)$ \\
\hline
\end{tabular}

Table S8. Effective SHG coefficients for EBOSI, KDP, KTP, and AGS.

\begin{tabular}{lcc}
\hline Compound & $\left\langle\boldsymbol{d}_{\text {eff }}\right\rangle(\mathbf{p m} / \mathbf{V})$ & Frequency of incident light $(\mathbf{n m})$ \\
\hline EBOSI & $5.42 / 1.93$ & $1064 / 2100$ \\
KDP & 0.33 & 1064 \\
KTP & $5.55,7.64$ & 1064 \\
AGS & $14.67 / 10.47$ & $1064 / 2100$ \\
\hline
\end{tabular}


Table S9. Calculated Mulliken bond populations of EBOSI.

\begin{tabular}{|c|c|c|}
\hline Bond & Population & Length $(\AA)$ \\
\hline \multirow[t]{18}{*}{$\mathrm{Eu}-\mathrm{O}$} & 0.08 & 2.56257 \\
\hline & 0.05 & 2.56784 \\
\hline & 0.07 & 2.58249 \\
\hline & 0.09 & 2.59671 \\
\hline & -0.03 & 2.62995 \\
\hline & -0.06 & 2.64589 \\
\hline & 0.05 & 2.64792 \\
\hline & -0.01 & 2.65452 \\
\hline & -0.00 & 2.66448 \\
\hline & 0.07 & 2.66964 \\
\hline & 0.06 & 2.67742 \\
\hline & 0.07 & 2.72071 \\
\hline & 0.03 & 2.88559 \\
\hline & 0.02 & 2.95876 \\
\hline & 0.01 & 2.96537 \\
\hline & -0.12 & 3.10299 \\
\hline & -0.09 & 3.16195 \\
\hline & -0.03 & 3.23554 \\
\hline $\operatorname{Eu}(1)-S(1 \mathrm{~A})$ & 0.28 & 2.88992 \\
\hline $\mathrm{Eu}(1)-\mathrm{S}(1 \mathrm{~B})$ & 0.22 & 2.96510 \\
\hline $\mathrm{Eu}(2)-\mathrm{S}(1 \mathrm{~A})$ & 0.23 & 2.95951 \\
\hline $\mathrm{Eu}(2)-\mathrm{S}(1 \mathrm{~B})$ & 0.32 & 2.80050 \\
\hline $\operatorname{Eu}(3)-S(1 A)$ & 0.42 & 2.82920 \\
\hline $\mathrm{Eu}(3)-\mathrm{S}(1 \mathrm{~B})$ & 0.33 & 2.98219 \\
\hline $\mathrm{Eu}(1)-\mathrm{I}(1)$ & -0.44 & 3.25215 \\
\hline $\mathrm{Eu}(2)-\mathrm{I}(1)$ & -0.47 & 3.23517 \\
\hline \multirow[t]{4}{*}{$\mathrm{B}-\mathrm{O}$} & 0.84 & 1.33672 \\
\hline & 0.87 & 1.34417 \\
\hline & 0.86 & 1.34761 \\
\hline & S16 & \\
\hline
\end{tabular}




\begin{tabular}{ll}
0.90 & 1.37255 \\
0.82 & 1.38305 \\
0.81 & 1.39514 \\
0.75 & 1.43623 \\
0.70 & 1.45462 \\
0.66 & 1.45716 \\
0.68 & 1.47075 \\
0.64 & 1.47096 \\
0.70 & 1.47120 \\
0.70 & 1.47375 \\
0.60 & 1.48167 \\
0.68 & 1.49132 \\
0.62 & 1.49651 \\
0.60 & 1.50121 \\
0.58 & 1.55563 \\
\hline
\end{tabular}

Table S10. Performance comparison for EBOSI and famous sulfide and borate NLO crystals.

\begin{tabular}{|c|c|c|c|c|c|c|c|}
\hline \multicolumn{2}{|c|}{ Compound } & $\begin{array}{l}\text { Point } \\
\text { group }\end{array}$ & $E_{g}(e V)$ & $d_{\mathrm{ijk}} / d_{\mathrm{eff}}(\times \mathrm{AGS})$ & $\begin{array}{c}\text { LIDT } \\
(\times \text { AGS })\end{array}$ & $\Delta \mathbf{n}$ & Ref. \\
\hline \multirow{3}{*}{ sulfide } & $\mathrm{AgGaS}_{2}(\mathrm{AGS})$ & $\overline{4} 2 m$ & $2.62-2.76$ & - & - & 0.05 & 1 \\
\hline & $\mathrm{LiGaS}_{2}$ (LGS) & $m m 2$ & $3.62-4.15$ & $0.45 / 0.31$ & 11 & 0.04 & 2,3 \\
\hline & $\mathrm{LiInS}_{2}$ (LIS) & $m m 2$ & $3.56-3.6$ & $0.68 / 0.41$ & 2.5 & $0.01-0.04$ & 2,3 \\
\hline \multirow{2}{*}{ borate } & $\mathrm{LiB}_{3} \mathrm{O}_{5}(\mathrm{LBO})$ & $m m 2$ & $7.75-7.78$ & $0.04 / 0.03$ & 30 & 0.04 & 1 \\
\hline & $\beta-\mathrm{BaB}_{2} \mathrm{O}_{4}(\mathrm{BBO})$ & $3 m$ & $6.2-6.43$ & $0.09 / 0.12$ & 150 & 0.11 & 1 \\
\hline sulfide borate & EBOSI & $m m 2$ & 1.98 & $0.37 / 0.27$ & 15 & 0.03 & This work \\
\hline
\end{tabular}

\section{Supplementary Discussion}

\section{Charge-transfer state (CTS) transition}

The peaks centered at $\sim 40899,44833$ and $50000 \mathrm{~cm}^{-1}$ are from electron transition and the first two are mainly from the S-3p orbital to the empty 4 f orbital of $\operatorname{Eu}^{3+}(\operatorname{Eu}(2)$ ) (Supplementary Figs. 2, and 3c), The broad charge transfer band (CTB) in $10000-38000 \mathrm{~cm}^{-1}$ wavelength range 
arises from two different mechanisms ${ }^{4}$. The first is host absorption band which involves electron transfer from $\mathrm{O}^{2-}$ and $\mathrm{S}^{2-}$ ligand to $\mathrm{Eu}^{3+}$. Abroad band at $\sim 33547 \mathrm{~cm}^{-1}(298 \mathrm{~nm})$ could be ascribed as the ligand-to-Eu ${ }^{3+}$ charge-transfer transitions (LMCT), because an electron transferred from the $\mathrm{O} 2 \mathrm{p}$ and S $3 \mathrm{p}$ orbital to the empty $4 \mathrm{f}$ orbital of $\mathrm{Eu}^{5}$.

Since Pauling electronegativity of $\mathrm{O}(\sim 3.44)$ is higher than $\mathrm{S}(\sim 2.58)^{25}$; it would be easier for $\mathrm{Eu}^{3+}$ to change oxidized thereby lowering the $\mathrm{Eu}^{3+}-\mathrm{S}^{2-}$ bond energy compared to $\mathrm{Eu}^{3+}-\mathrm{O}^{2-}$. Thus, the LMCT peak of sulfide borate is widened and red-shifted compared with the general oxide containing $\mathrm{Eu}^{3+} .4,5$ The weak band at $6264 \mathrm{~cm}^{-1}$ will not be further considered because of lack of information on its polarization and its behavior in various crystal treatments ${ }^{6}$.

The second contribution to CTB is inter-valence charge transfer (IVCT) states. IVCT states usually leads to an energy band at lower energy compared to the inter band electron transition energy. Hence this is usually observed as a shoulder on the lower energy side of the CTB. The broad peak centered at $\sim 17077 \mathrm{~cm}^{-1}$ can be attributed to the IVCT absorption according to other experimental studies of similar mixed-valence compounds ${ }^{7,8}$.

For powder samples, no quantitative data can be extracted from the diffuse reflection spectra ${ }^{9}$ CATEP can predict the absorption coefficients of crystals and correspond well with the experimental results in the energy range of only interband transitions ${ }^{10}$. So, the absolute absorption coefficient calculated by theory is used to correct the measured spectrum.

Optical transition which involves transfer of an electron from donor to acceptor being metal ions which possess more than one accessible oxidation state. For mixed oxidation-state compounds, both donor and acceptor are ions of the same element. In $\mathrm{EBOS}, \mathrm{Eu}^{2+}$ and $\mathrm{Eu}^{3+}$ are donors and acceptors by ligand atom S and $\mathrm{O}$ (Figure S8b). Here, space wave functions of donor and acceptor orbitals set to $\psi_{d}$ and $\psi a$, respectively. There will usually be some mixing between these configurational states and, therefore mixed ground state $|0\rangle$ and excited state $|1\rangle$ expressions are,

$$
\begin{aligned}
& |0\rangle=\psi_{d}+\xi \psi_{a} \\
& |1\rangle=\xi \psi_{d}-\psi_{a}
\end{aligned}
$$

where $\xi$ is the mixing coefficient.

Transition dipole moment $\boldsymbol{M}_{01}$ between $|0\rangle$ and excited state $|1\rangle$ is given by

$$
\boldsymbol{M}_{01}=e \sum_{i}\left\langle 0\left|e r_{i}\right| 1\right\rangle
$$

The magnitude of $\boldsymbol{M}_{01}$ is

$$
\left|\boldsymbol{M}_{01}\right|=e \xi r
$$

where $r$ is the donor-acceptor internuclear distance. 
Oscillator strength $f$ of IVCT can be estimated from formulas,

$$
f=4.32 \times 10^{-9} \int \epsilon d \bar{v}=1.085 \times 10^{-5} \bar{v} D^{2}
$$

Where $\epsilon$ is the molar absorption coefficient of the band maximum, $\bar{v}$ the frequency in $\mathrm{cm}^{-1}$, and $D=\left|\mathbf{M}_{01}\right| / \mathrm{e}$ in $\AA$, thus $f=0.19$ for IVCT,

For a pair of adjacent $\mathrm{Eu}^{3+}$ and $\mathrm{Eu}^{2+}$ ions, the dipole strength $D^{1}$ calculated for a one-electron transition,

$$
D^{1}=\xi r
$$

where $r=4.17 \AA$. Since there are 7 electrons in the donor orbitals and each electron can jump to any one of 3 adjacent acceptor states, so that the resultant $\boldsymbol{D}$ is,

$$
\mathrm{D}=\sqrt{7 \times 3} D^{1}=\sqrt{21} \xi r
$$

so that $\mathrm{D}=1.018 \AA$. Therefore, $\xi=0.05323$ and $\xi^{2}=2.833 \times 10^{3}$.

Summing over all three acceptor sites, this implies that the $\mathrm{Eu}^{2+}$ electrons are $99.15 \%$ associated with the donor ion in the ground state of the crystal.

\section{Bader charges}

The Bader charge analysis ${ }^{11}$ for EBOS and EBOSI were calculated by CASTEP and calculating parameter settings are the same as section 2.1 and 2.3.

The analysis of EBOS shows that the $\mathrm{Eu}(1), \mathrm{Eu}(2)$ and $\mathrm{B}$ atoms lose the valence charge by the amounts of $1.69,1.73$, and 2.95 to form $\mathrm{Eu}(1)^{1.69+}, \mathrm{Eu}(2)^{1.73+}$ and $\mathrm{B}^{2.95+}$ cations, respectively, whereas the $\mathrm{O}$, and $\mathrm{S}$ atoms gain the valence charges by the amounts of 1.91 and 0.97 in average to create $\mathrm{O}^{1.91-}$ and $\mathrm{S}^{0.97-}$ anions, respectively.

The analysis of EBOSI shows that the Eu and B atoms lose the valence charge by the amounts of 1.55 and 3.00 to form $\mathrm{Eu}^{1.55+}$ and $\mathrm{B}^{3.00+}$ cations, respectively, whereas the $\mathrm{O}, \mathrm{S}$, and I atoms gain the valence charges by the amounts of $1.94,1.33$, and 0.68 in average to create $\mathrm{O}^{1.94-}, \mathrm{S}^{1.33-}$, and $\mathrm{I}^{0.68-}$ anions, respectively.

\section{Symmetry analysis of the SHG tensor elements $\chi_{i j k}^{(2)}$}

There are 27 components of the SHG tensors as shown in the following Supplementary Table. Based on the point group $m m 2$ (the two-fold axis along the $z$ axis), the noncentrosymmetric EBOSI (space group No. 34, Pnn2) matrix has seven non-zero SHG coefficients, which are indicated with in bold. 


$$
\chi_{i j k}^{(2)}=\left[\begin{array}{llllllllll}
\chi_{111}^{(2)} & \chi_{122}^{(2)} & \chi_{133}^{(2)} & \chi_{123}^{(2)} & \chi_{113}^{(2)} & \chi_{112}^{(2)} & \chi_{132}^{(2)} & \chi_{131}^{(2)} & \chi_{121}^{(2)} \\
\chi_{211}^{(2)} & \chi_{222}^{(2)} & \chi_{233}^{(2)} & \chi_{223}^{(2)} & \chi_{213}^{(2)} & \chi_{212}^{(2)} & \chi_{232}^{(2)} & \chi_{231}^{(2)} & \chi_{221}^{(2)} \\
\chi_{311}^{(2)} & \chi_{322}^{(2)} & \chi_{333}^{(2)} & \chi_{323}^{(2)} & \chi_{313}^{(2)} & \chi_{312}^{(2)} & \chi_{332}^{(2)} & \chi_{331}^{(2)} & \chi_{321}^{(2)}
\end{array}\right]
$$

By the intrinsic symmetry,

$$
\begin{aligned}
& \chi_{113}^{(2)}=\chi_{131}^{(2)} \\
& \chi_{223}^{(2)}=\chi_{232}^{(2)}
\end{aligned}
$$

\section{Length-gauge formulations with scissors correction}

Scissors implementation within length-gauge formulations of the frequency-dependent NLO response equations used to calculate the second-order response function were originally derived by Aversa and $\mathrm{Sipe}^{12}$ and later modified by F. Nastos et $a l^{13}$. The spectrum is computed by using the symmetry, in which the interband transitions $\chi_{i n t e r}^{a b c}(2 \omega, \omega, \omega)$, the intraband transitions $\chi_{\text {intra }}^{a b c}(2 \omega, \omega, \omega)$, and the modulation of interband terms by intraband terms $\chi_{m o d}^{a b c}(2 \omega, \omega, \omega)$ as the contributions to the SHG susceptibility ${ }^{14}$ :

$\chi_{\text {inter }}^{\text {abc }}(2 \omega, \omega, \omega)$

$$
\begin{aligned}
& =\frac{1}{\Omega} \sum_{n m l k}^{\prime} W_{k} \times\left\{\frac{2 r_{n m}^{a}\left\{r_{m l}^{b} r_{l n}^{c}\right\}}{\left(\omega_{l n}-\omega_{m l}\right)\left(\omega_{m n}-2 \omega\right)}\right. \\
& \left.-\frac{1}{\left(\omega_{m n}-\omega\right)}\left[\frac{r_{l m}^{c}\left\{r_{m n}^{a} r_{n l}^{b}\right\}}{\left(\omega_{n l}-\omega_{m n}\right)}-\frac{r_{n l}^{b}\left\{r_{l m}^{c} r_{m n}^{a}\right\}}{\left(\omega_{l m}-\omega_{m n}\right)}\right]\right\}
\end{aligned}
$$

$\chi_{\text {intra }}^{a b c}(2 \omega, \omega, \omega)$

$$
\begin{aligned}
& =\frac{1}{\Omega} \sum_{k} W_{k}\left\{\sum_{n m l}^{\prime} \frac{\omega_{m n}^{-2}}{\left(\omega_{m n}-\omega\right)} \times\left[\omega_{l n} r_{n l}^{b}\left\{r_{l m}^{c} r_{m n}^{a}\right\}-\omega_{m l} r_{l m}^{c}\left\{r_{m n}^{a} r_{n l}^{b}\right\}\right]\right. \\
& \left.-8 \mathrm{i} \sum_{n m}^{\prime} \frac{1}{\omega_{m n}^{2}\left(\omega_{m n}-2 \omega\right)} r_{m n}^{a}\left\{\Delta_{m n}^{b} \gamma_{l n}^{c}\right\}+2 \sum_{n m l}^{\prime} \frac{r_{n m}^{a}\left\{r_{m l}^{b} r_{l n}^{c}\right\}\left(\omega_{m l}-\omega_{l n}\right)}{\omega_{m n}^{2}\left(\omega_{m n}-2 \omega\right)}\right\}
\end{aligned}
$$

$$
\begin{aligned}
& \chi_{m o d}^{a b c}(2 \omega, \omega, \omega) \\
& =\frac{1}{2 \Omega} \sum_{k} W_{k}\left\{\sum_{n m l} \frac{1}{\omega_{m n}^{2}\left(\omega_{m n}-\omega\right)} \times\left[\omega_{n l} r_{l m}^{a}\left\{r_{m n}^{b} r_{n l}^{c}\right\}-\omega_{l m} r_{n l}^{a}\left\{r_{l m}^{b} r_{m n}^{c}\right\}\right]\right. \\
& \left.-\mathrm{i} \sum_{n m} \frac{r_{n m}^{a}\left\{r_{m n}^{b} \Delta_{m n}^{c}\right\}}{\omega_{m n}^{2}\left(\omega_{m n}-\omega\right)}\right\}
\end{aligned}
$$




\section{Effective SHG response $\left\langle d_{e f f}\right\rangle$}

To assess powder SHG response of EBOSI, the effective second-order NLO coefficient $\left\langle d_{e f f}\right\rangle$ can be calculated by the formula derived by Kurtz-Perry ${ }^{15}$ and Cyvin et al ${ }^{16}$. based on the calculated NLO tensors $d_{i j k}\left(=\frac{1}{2} \chi_{i j k}^{(2)}\right)$, for $m m 2$ point group (the two-fold axis along the $z$ axis),

$$
\begin{gathered}
\left\langle\left(d_{e f f}\right)^{2}\right\rangle=\left(\frac{19}{105}\right)\left(d_{333}\right)^{2}+\left(\frac{13}{105}\right)\left(d_{333} d_{311}+d_{333} d_{322}\right)+\left(\frac{44}{105}\right)\left[\left(d_{223}\right)^{2}+\left(d_{113}\right)^{2}\right] \\
+\left(\frac{13}{105}\right)\left(d_{223} d_{311}+d_{113} d_{322}\right)
\end{gathered}
$$

\section{References}

1 Nikogosyan, D. N. Nonlinear optical crystals: a complete survey. Springer Science \& Business Media, 2006.

2 Isaenko, L. I.; Vasilyeva, I. G. Nonlinear $\mathrm{LiB}^{\mathrm{III}} \mathrm{C}^{\mathrm{YI}}{ }_{2}$ crystals for mid-IR and far-IR: Novel aspects in crystal growth. J. Cryst. Growth 2008, 310, 1954-1960.

3 K. Wu,; B. B. Zhang,; Z. H. Yang,; Pan, S. L. New Compressed Chalcopyrite-like $\mathrm{Li}_{2} \mathrm{BaM}^{\mathrm{IV}} \mathrm{Q}_{4}\left(\mathrm{M}^{\mathrm{IV}}=\mathrm{Ge}, \mathrm{Sn} ; \mathrm{Q}=\mathrm{S}, \mathrm{Se}\right)$ : Promising Infrared Nonlinear Optical Materials. J. Am. Chem. Soc. 2017, 139, 14885-14888.

4 Keskar, M.; Gupta, S. K.; Phatak, R.; Kannan, S.; Natarajan, V. Optical properties of Eu ${ }^{3+}$ activated thorium molybdate and thorium tungstate: Structure, local symmetry and photophysical properties. J. Photoch. Photobio. A 2015, 311, 59-67.

5 Li, Y. C.; Chang, Y. H.; Lin, Y. F.; Chang, Y. S.; Lin, Y. J. Synthesis and luminescent properties of $\mathrm{Ln}^{3+}\left(\mathrm{Eu}^{3+}, \mathrm{Sm}^{3+}, \mathrm{Dy}^{3+}\right)$-doped lanthanum aluminum germanate $\mathrm{LaAlGe}_{2} \mathrm{O}_{7}$ phosphors. J. Alloy. \& Compd. 2007, 439, 367-375.

6 Martinat, B.; Gourier, D.; Lejus, A. M.; Vivien, D. J. Optical properties of $\operatorname{LaMgAl}_{11} \mathrm{O}_{19}$ : $\mathrm{Ti}^{3+}$, a potential tunable laser material. Solid State Chem. 1990, 89, 147-154.

7 Wickleder, C. A new mixed valent europium chloride: $\mathrm{Na}_{5} \mathrm{Eu}_{7} \mathrm{Cl}_{22}$. Z. Naturforsch. B 2002, 57, 901-907.

8 Wickleder, C. Z. $\mathrm{KEu}_{2} \mathrm{Cl}_{6}$ und $\mathrm{K}_{1,6} \mathrm{Eu}_{1,4} \mathrm{Cl}_{5}$ : Zwei neue gemischtvalente Europiumchloride. Z. Anorg. Allg. Chem. 2002, 628, 1815-1820.

9 Horneffer, V.; Dreisewerd, K.; Lüdemann, H. C.; Hillenkamp, F.; Läge, M.; Strupat, K. Is the incorporation of analytes into matrix crystals a prerequisite for matrix-assisted laser 
desorption/ionization mass spectrometry? A study of five positional isomers of dihydroxybenzoic acid. Int. J. Mass Spectrom. 1999, 185, 859-870.

10 Zhang, P.; Zhou, Y. R.; Yan, Q. B.; Liu, F. Z.; Li, J. W.; Dong, G. Q. A combined experimental-computational study on nitrogen doped $\mathrm{Cu}_{2} \mathrm{O}$ as the wide-spectrum absorption material. J. Semicond. 2014, 35, 103001.

11 Tang, W.; Sanville, E.; Henkelman, G. A grid-based Bader analysis algorithm without lattice bias. J. Phys.: Condens. Matter. 2009, 21, 084204.

12 Aversa, C.; Sipe, J. E. Nonlinear optical susceptibilities of semiconductors: Results with a length-gauge analysis. Phys. Rev. B 1995, 52, 14636.

13 Nastos, F.; Olejnik, B.; Schwarz, K.; Sipe, J. E. Scissors implementation within lengthgauge formulations of the frequency-dependent nonlinear optical response of semiconductors. Phys. Rev. B 2005, 72, 045223.

14 Sharma, S.; Ambrosch-Draxl, C. Second-harmonic optical response from first principles. Physica Scripta. 2004, T109, 128.

15 Kurtz, S. K.; Perry, T. T. A powder technique for the evaluation of nonlinear optical materials. J. App. Phys. 1968, 39, 3798-3813.

16 Cyvin, S. J.; Rauch, J. E.; Decius, J. C. Theory of Hyper-Raman Effects (Nonlinear Inelastic Light Scattering): Selection Rules and Depolarization Ratios for the SecondOrder Polarizability. J. Chem. Phys. 1965, 43, 4083-4095. 